\title{
Paradigm Foundations of Modern Science: Self-Organization, Evolution, Integrity
}

\author{
Natalya Zinovyevna Alieva \\ Zoya Viktorovna Zayats
}

Don State Technical University Email: alinat1@yandex.ru

\section{Doi:10.5901/mjss.2015.v6n3s4p97}

\begin{abstract}
An attempt of constructing paradigm foundations of modern science, which are rooted in the uniform concept of selforganization, in which holism, evolution and self-organization are interconnected in a triune whole is presented in article. The conceptual basis of the research is the idea of unity of integrity - evolution - self-organization. The integrated framework representing a holographic effect of comprehensive, holistic vision of the integrated world will be the result of interconnection of the enumerated concepts. At the present stage the interdisciplinary sphere which one side is the scientific knowledge, its structure and dynamics, and the second - connection of scientific knowledge and scientific world outlook with a person, his ideals, purposes, values has to perform a function of methodology. From our point of view, the presentation of the concept "integrity - evolution - self-organization" constructed in this article is one of the attempts of this sort of reflection.
\end{abstract}

Keywords: Paradigm foundations, a modern science, a concept, self-organization, evolution, integrity.

\section{Introduction}

Constructing paradigm foundations of modern science it is necessary to use the concepts of self-organization, evolution and integrity. Interweaving, coherently interconnecting them and creating the integrated framework representing a holographic effect of comprehensive, holistic vision of the integrated world. The conceptual basis of our research is the idea of unity of integrity - evolution - self-organization. In what follows we will name it the concept of complexity, because it represents complexity of the world and its various spheres and resonates with notions of complex thinking.

If earlier as the methodology of natural science philosophy of science acted, at the present stage the interdisciplinary sphere which one side is the scientific knowledge, its structure and dynamics, and the second connection of scientific knowledge and scientific world outlook with a person, his ideals, purposes, values has to perform such function. Philosophy of science also has to become such sphere.

Thus, actualizing problems of philosophy of modern science which has to reflect the possibility of implementation of interdisciplinary scientific researches, and also connection of natural-science and humanitarian knowledge. Among the attempts of this sort of reflection is the presentation of the concept "integrity - evolution - self-organization" constructed in this article.

\section{The Concept of Self-Organization}

The second paradigm foundation of modern science is the concept of universal evolutionism, which was born also in post-nonclassical natural science. The synergetic outlook caused emergence of the idea of integrity of inorganic nature and wildlife, Nature and Person, Space and Earth, matter and thinking. All listed phenomenon are connected by evolution to wide extent. Evolution of the space is continuing in biological evolution. Biological evolution is continuing in human history. What will happen in the future? How there will be the development of the Universum, mankind, society, its social institutes together with science? These questions are answered by the evolutionary concept.

The history of formation of evolutionary views in science can be conditionally divided into some stages. The first stage - an anti-evolutionism - is characterized by the absolute denial of any evolutionary changes and is representative of the classical picture of the world. In theological version the anti-evolutionism declares one-time creation by the Creator of all elements of the world. The second stage - local evolutionism - is characteristic for science of the second half of XIXth - the beginning of the XXth centuries. All evolutionary processes (biological evolution, development of cosmological objects) were considered locally, but not as the interconnected stages of the development of the 
Universum. The third stage - global (universal) evolutionism - began to develop at the end of the XXth century (L.M. Gindelis, I. Prigozhin, Teillar de Chardin, E. Yanch, G. M. Idlis, N. N. Moiseyev, V. V. Kazyutinsky, A.P. Nazaretyan, etc.). Its basic propositions are as follows: the world has the beginning in time and consists of the hierarchical systems (elementary particles - atoms - molecules - organisms - social system), consecutive appearing from the moment of its emergence as the stages of its evolution; the laws of functioning of systems are recognized as invariable throughout the evolution of the World. The concept of global evolutionism expanded the borders of the evolutionary approach accepted in biological and social sciences into all spheres of the Universum. The concept of global evolution extends the evolutionary view to all types of movement, to all Universe, to all stages of its history, including the moment of its Beginning.

But some authors, for example A.V. Boldachev, consider that "at every moment of the history of the Universe it is possible to distinguish only two evolutionary systems - the whole world and the type of movement which is vanguard of evolution at the moment", and "separate evolutionary processes (for example, biological or social) are not subordinate elements of global evolution, they are evolution per se, its private implementations at concrete stages of the history of the Universe" (Schrodinger, 1976).

Opponents of the evolutionary idea claim that evolutionism is not science and represents a kind of the ideology, which was very popular in the conditions of increasing mass disbelief. They claim that evolutionism does not answer scientific criteria of verifiability and falsifiability because the idea of evolutionism can neither be confirmed nor disproved.

For substantiation of truth of the idea of global evolutionism special value has the theory of evolution of the biosphere and the noosphere created in the 1920s of the XXth century by V. I. Vernadsky. From his point of view, the biosphere as a special geological body represents the complete system possessing the highest extent of selforganization and ability to evolve. To a considerable extent its functioning is determined by "existence in it of living material - population of living organisms, existing in it". Under the influence of scientific thought and human labour the biosphere passes into a new state - the noosphere. At the same time position of a person on the planet changes - he becomes the powerful geological force, which unites in a single whole both mankind and all processes in the biosphere.

As we already noted above, evolutionary ideas about the world are conformable to synergetic views. The theory of dissipative structures allows to establish the evolutionary paradigm for micro, macro and mega levels. The evolutionary paradigm has application borders which are outlined, first, by the closed systems striving for chaos, and, secondly, by the open systems developing to higher levels of complexity.

Thus, universal evolutionism, representing both a concept and a world outlook phenomenon, causes need of reconsideration of problems of development, time, fortuity, universal connection, and also application of an interdisciplinary approach to their studying. The most important result of the idea of universal evolutionism is the "holographic view" of the world, which actively influences through worldview attitudes a choice of priorities of human existence, and also a direction of social process in general. This is the world outlook function of the idea of universal evolutionism.

The defining role in the strengthening of universal evolutionism as modern general scientific worldview strategy was played in science of the XX century by the following conceptual schools: the theory of the non-stationary Universe, synergetics, the theory of biological evolution and the concept of the biosphere and the noosphere, and also dialectics developed on its basis. According to the theory of the extending Universe, 15-20 billion years ago from the point of singularity as a result of the Big Bang began the expansion of the Universe which evolved to variety of space bodies. The theory of self-organization including all processes of self-structuring, self-regulation, self-reproduction, connected with the idea of universal evolutionism, looks for the universal evolutionary laws describing the development of systems of different nature in a unified manner, as led to inclusion of the anthropic principle in the theory of the extending evolving Universe. According to this principle, the Universe has to be such that at some stage of evolution existence of observers was allowed.

The idea of universal evolutionism, having become transdisciplinary, runs through all existing specialized scientific worldviews. It is a basis of construction of the complete general scientific worldview, which acts as the global research program defining the strategy of research of self-developing systems.

It should be especially noted that the idea of universal evolutionism has a humanistic focus, promotes the synthesis of natural-science concepts and principles with ethical, moral categories, such as responsibility, freedom, ideal, belief, sense. Within the framework of universal evolutionism ontologic views are closely interwoven with ethical views. So, the Universum becomes "proportional" to a Person, and at the same time a person and mankind become proportional to the universal evolutionary process. Universal evolutionism represents organic merging of science and ethics in the uniform scientific-theoretical concept.

The ideas of universal evolutionism, having received an impulse to the development from the theory of self- 
organization of complex systems, were formed conceptually into universal evolutionism (Moeseev, 2001), the new natural-science concept of development (R. Rovinsky), global evolutionism (V. Kazyutinsky, R. Karpinskaya). So, R. Rovinsky considers that "the natural-science concept of development is a through product of scientific knowledge level and extent of its generalization reached for the moment, it changes together with the change of the last", and it "should not be confused" "to philosophical concepts of development, which can be several at the same time and everyone is opposed to all another" (Rovinsky, http://astrophisics.boom.ru/).

\section{The Concept of Universal Evolutionism}

The second paradigm foundation of modern science is the concept of universal evolutionism, which was born also in post-nonclassical natural science. The synergetic outlook caused emergence of the idea of integrity of inorganic nature and wildlife, Nature and Person, Space and Earth, matter and thinking. All listed phenomenon are connected by evolution to wide extent. Evolution of the space is continuing in biological evolution. Biological evolution is continuing in human history. What will happen in the future? How there will be the development of the Universum, mankind, society, its social institutes together with science? These questions are answered by the evolutionary concept.

The history of formation of evolutionary views in science can be conditionally divided into some stages. The first stage - an anti-evolutionism - is characterized by the absolute denial of any evolutionary changes and is representative of the classical picture of the world. In theological version the anti-evolutionism declares one-time creation by the Creator of all elements of the world. The second stage - local evolutionism - is characteristic for science of the second half of XIXth - the beginning of the XXth centuries. All evolutionary processes (biological evolution, development of cosmological objects) were considered locally, but not as the interconnected stages of the development of the Universum. The third stage - global (universal) evolutionism - began to develop at the end of the XXth century (L.M. Gindelis, I. Prigozhin, Teillar de Chardin, E. Yanch, G. M. Idlis, N. N. Moiseyev, V. V. Kazyutinsky, A.P. Nazaretyan, etc.). Its basic propositions are as follows: the world has the beginning in time and consists of the hierarchical systems (elementary particles - atoms - molecules - organisms - social system), consecutive appearing from the moment of its emergence as the stages of its evolution; the laws of functioning of systems are recognized as invariable throughout the evolution of the World. The concept of global evolutionism expanded the borders of the evolutionary approach accepted in biological and social sciences into all spheres of the Universum. The concept of global evolution extends the evolutionary view to all types of movement, to all Universe, to all stages of its history, including the moment of its Beginning.

But some authors, for example A.V. Boldachev, consider that "at every moment of the history of the Universe it is possible to distinguish only two evolutionary systems - the whole world and the type of movement which is vanguard of evolution at the moment", and "separate evolutionary processes (for example, biological or social) are not subordinate elements of global evolution, they are evolution per se, its private implementations at concrete stages of the history of the Universe" (Schrodinger, 1976).

Opponents of the evolutionary idea claim that evolutionism is not science and represents a kind of the ideology, which was very popular in the conditions of increasing mass disbelief. They claim that evolutionism does not answer scientific criteria of verifiability and falsifiability because the idea of evolutionism can neither be confirmed nor disproved.

For substantiation of truth of the idea of global evolutionism special value has the theory of evolution of the biosphere and the noosphere created in the 1920s of the XXth century by V. I. Vernadsky. From his point of view, the biosphere as a special geological body represents the complete system possessing the highest extent of selforganization and ability to evolve. To a considerable extent its functioning is determined by "existence in it of living material - population of living organisms, existing in it". Under the influence of scientific thought and human labour the biosphere passes into a new state - the noosphere. At the same time position of a person on the planet changes - he becomes the powerful geological force, which unites in a single whole both mankind and all processes in the biosphere.

As we already noted above, evolutionary ideas about the world are conformable to synergetic views. The theory of dissipative structures allows to establish the evolutionary paradigm for micro, macro and mega levels. The evolutionary paradigm has application borders which are outlined, first, by the closed systems striving for chaos, and, secondly, by the open systems developing to higher levels of complexity.

Thus, universal evolutionism, representing both a concept and a world outlook phenomenon, causes need of reconsideration of problems of development, time, fortuity, universal connection, and also application of an interdisciplinary approach to their studying. The most important result of the idea of universal evolutionism is the "holographic view" of the world, which actively influences through worldview attitudes a choice of priorities of human existence, and also a direction of social process in general. This is the world outlook function of the idea of universal 
evolutionism.

The defining role in the strengthening of universal evolutionism as modern general scientific worldview strategy was played in science of the XX century by the following conceptual schools: the theory of the non-stationary Universe, synergetics, the theory of biological evolution and the concept of the biosphere and the noosphere, and also dialectics developed on its basis. According to the theory of the extending Universe, 15-20 billion years ago from the point of singularity as a result of the Big Bang began the expansion of the Universe which evolved to variety of space bodies. The theory of self-organization including all processes of self-structuring, self-regulation, self-reproduction, connected with the idea of universal evolutionism, looks for the universal evolutionary laws describing the development of systems of different nature in a unified manner, as led to inclusion of the anthropic principle in the theory of the extending evolving Universe. According to this principle, the Universe has to be such that at some stage of evolution existence of observers was allowed.

The idea of universal evolutionism, having become transdisciplinary, runs through all existing specialized scientific worldviews. It is a basis of construction of the complete general scientific worldview, which acts as the global research program defining the strategy of research of self-developing systems.

It should be especially noted that the idea of universal evolutionism has a humanistic focus, promotes the synthesis of natural-science concepts and principles with ethical, moral categories, such as responsibility, freedom, ideal, belief, sense. Within the framework of universal evolutionism ontologic views are closely interwoven with ethical views. So, the Universum becomes "proportional" to a Person, and at the same time a person and mankind become proportional to the universal evolutionary process. Universal evolutionism represents organic merging of science and ethics in the uniform scientific-theoretical concept.

The ideas of universal evolutionism, having received an impulse to the development from the theory of selforganization of complex systems, were formed conceptually into universal evolutionism (Moeseev, 2001), the new natural-science concept of development (R. Rovinsky), global evolutionism (V. Kazyutinsky, R. Karpinskaya). So, R. Rovinsky considers that "the natural-science concept of development is a through product of scientific knowledge level and extent of its generalization reached for the moment, it changes together with the change of the last", and it "should not be confused" "to philosophical concepts of development, which can be several at the same time and everyone is opposed to all another" (Rovinsky, http://astrophisics.boom.ru/).

\section{Concept of Integrity}

The third paradigm foundation of modern science became the concept of integrity. For the completion of construction of the triune concept of self-organization we will consider the problem of integrity and find out how developed natural science from a reductionism to a holism. It is written so much about integrity, holism, integration, consolidation, synthesis, that willy-nilly arises a question, what new our research can add to the concept of integrity?

The importance and necessity of philosophical reflection over the problem of integrity for the sphere of science and education is connected with finding of such metapoints of view on science and education, which will allow to connect and organize the accumulated knowledge and to learn the world in its entirety and integrity. Such problem statement demands a paradigm reform of thinking that inevitably has to lead to an education reform. Edgar Moren writes in this regard: "... Our separated, split up, distributed among disciplinary areas knowledge is deep, even terribly inadequate for comprehension of today's realities and problems which become more and more global, transnational, multidimensional and planetary. Because of this inadequacy become invisible: Context, Global, Multidimensional, Complex" (Moren, 2007, p. 36).

The concept of integrity of scientific knowledge makes special demands of post-nonclassical education. First, it is necessary to educate in vision of the global in its capacity as an organizing whole, to form the attitude of thinking, according to which the whole has the property of self-reference: the whole is contained in parts: "... each separate cell, each certain individual contains holographically a whole which part he is and which at the same time is his part" (Морен, 2007, c. 37).

Secondly, it is necessary to show that the history of science is a dramatic search of the way to unite separate, "piecewise" scientific knowledge into integrity. The purpose of science - to create the unified theory of "everything in the world" - combines paradoxically the desire of achievement and real unattainability of this desire. "A modern western civilization, - Oliver Toffler wrote in this regard, - reached extraordinary achievements in the art of disintegration of the whole on parts, namely - in decomposition of the whole on the smallest components. We fairly succeeded in this art, succeeded so that quite often we forget to integrate decomposed parts in that whole which they once compose. Especially sophisticated forms the art of decomposition of the whole on components took in science. We used not only to 
smash any problem into shivers byte or even less in size, but also quite often we isolate such shivers by means of very convenient trick. We say: "Ceteris paribus", and this spell allows us to neglect complex interrelations between the problem interesting us and other part of the Universe" (Prigogine, Stengers, http://spkurdyumov.narod.ru/KrStolSyner. htm).

Ilya Prigozhin, comprehending the developed priority of division into parts in science methodology, "the best years of the life ... devoted to reconstruction the whole from components, whether it be biology or physics, necessity or fortuity, natural or human sciences" (Prigogine, Stengers, http://spkurdyumov.narod.ru/KrStolSyner.htm). The first version of the book "Order out of chaos. Man's new dialogue with nature", appeared in 1979 in French, was called "New alliance" (La nouvelle alliance) that is possible to translate as a new union, new integration, new synthesis.

Post-nonclassical science showed that practically all urgent problems have a complex character, and therefore need creation of integral vision, view. The present stage of the development of world science is called the integrative revolution in knowledge. It is focused on understanding and disclosure of generality, integrity of the studied objects and phenomena. Researches of almost all problems of the present are aimed at synthesis, have the uniting character (Order out of chaos, http://spkurdyumov.narod.ru/Ppigogin/Priposleslovie.htm).

Modern views of synthesis and its searches find out that formation of integrity of knowledge happens not only due to process of synthesis, integration, but also due to implementation of processes of division, differentiation. The foundation of synthesis of natural-science knowledge are material unity of the world; universal connection of the phenomena and processes; the steady, repeating, invariant connections and the relations of subjects and processes of the real world; isomorphism in structure of the phenomena, various by the nature; general laws of their existence and development.

N. N. Moiseyev considered, that in overcoming of tendencies to differentiation of scientific knowledge the big role belongs to education, which has to overcome narrow specialization and promote formation of the integral idea of the world: "Crisis in relationship of the Nature and society promptly increases, and education has to be far beyond narrow professionalism. A modern person has to see the world in its integrity. Only the view of general logic of the development of that world where we live will help us to avoid catastrophic consequences of the crisis which inevitably approaches. And perhaps to avoid this crisis!" (Moeseev, 2001, pp. 11).

Making a typologization of the uniting aspirations in scientific knowledge, it is possible to distinguish synthesis across; vertical synthesis and holographic synthesis in the context of holodynamics. Synthesis across appears as consolidation of parts, elements of a system at one hierarchical level of the system, without excluding fragmentation at other levels of the system at the same time. Vertical synthesis assumes holism of higher level, but at the same time the reductionism at the lower levels of the system is observed. Holographic synthesis following from the holographic theory of the Universe, developed by David Bom, one of the most outstanding experts in the field of quantum physics. This kind of synthesis leads to conclusion about the existence of holographic integrity (wholeness). Michael Talbot interpreted the idea of holographic integrity in such way: "Our tangible daily reality in fact - only illusion, like a holographic image. There is deeper order of existence under it - the boundless and initial level of existence, - from which all objects are born and, including, visibility of our physical world similarly to how from a bit of a holographic film the hologram is born. Baume calls this deep level of reality implicative (that is "hidden") order, while our own level of existence he determines as explicative, or opened order" (Talbot, http://www.ligis.ru/librari/1764.htm).

All mentioned typologies of synthesis of scientific knowledge have a constructivist function. The first two types of synthesis represent holism of the post-nonclassical stage of the development of natural sciences, which carries the constructivist principles: formation of a complex evolutionary whole from parts; construction of different complex structures from the simple ones; creation through consolidation; unity through variety. The last principle explains and reconciles the different views of prevalence of processes of integration or differentiation, convergence or divergence, synthesis or analysis. There is no consolidation without division, there is no unity without variety. These principles allow not only to put the new of parts together, but also to gain a synergetic effect - the qualitatively new whole, not corresponding to the usual principle of superposition: the whole is not equal to the sum of the composed parts any more. All our world in conceptual vision of synergetics appears as a nonlinear. Creation means consolidation there. The principle "to create means to connect (unite)" was formulated by Tellar de Chardin. Synergetics included it in the concept (E.N. Knyazev, S.P. Kurdiumov). The third, holographic synthesis, is inherent in the nature, it is "nature" itself, the essence of the world. Its misunderstanding, recognition only of the existing way of fragmentation of the world, can be fatal. It is impossible to change a part of Earth, without causing changes of the Earth in general. It is impossible to solve separate problems of society, ignoring society in general, etc. 


\section{Conclusion}

Constructing the paradigm foundations of our research, it is necessary the concept of self-organization, evolution, integrity, interweaving, coherently interconnecting them and creating the integrated framework representing a holographic effect of comprehensive, holistic vision of the integrated world. The paradigm foundation of our research is the idea of unity of integrity - evolution - self-organization. It is also possible to call it the concept of complexity because it represents the complexity of the world and its various spheres and resonates with notions of complex thinking. If earlier as the methodology of natural science philosophy of science acted, at the present stage the interdisciplinary sphere which one side is the scientific knowledge, its structure and dynamics, and the second - connection of scientific knowledge and scientific world outlook with a person, his ideals, purposes, values has to perform such function. Philosophy of science also has to become such sphere.

Thus, actualizing problems of philosophy of modern science which has to reflect the possibility of implementation of interdisciplinary scientific researches, and also connection of natural-science and humanitarian knowledge. From our point of view, the presentation of the concept "integrity - evolution - self-organization" constructed in this article is one of the attempts of this sort of reflection.

\section{References}

Moeseev N.N. (2001). Universe. The Information. Society / NN Moiseev. - M .: Sustainable World. pp.200.

Moren E. (2007) Education of the Future: Seven urgent tasks / E. Morin // synergetic paradigm. Synergetics education. M. ProgressTradition. pp. 24-96.

Prigogine I. Order out of chaos. New dialogue with nature. / Prigogine, I. Stengers. - URL: http://spkurdyumov.narod.ru/Ppigogin/ Priposleslovie.htm.

Rovinsky R. Evolving universe / R. Rovinsky. - URL: http://astrophisics.boom.ru/

Synergetics: prospects, problems, difficulties: round table discussion. - URL: http://spkurdyumov.narod.ru/KrStolSyner.htm

Talbot M. Holographic Universe (Part 1-3) / Michael Talbot. - URL: http://www.ligis.rullibrari/1764.htm

Schrodinger E. (1976). Are there quantum jumps? / Schrodinger // Selected works on quantum mechanics. M. science. 